\title{
UNA MIRADA AL MUNDO LABORAL \\ ENTREVISTA A RODOLFO SEGUEL, EX DIPUTADO DC
}

\section{"LA LEY BUSTOS ES LA MÁS EMBLEMÁTICA DESDE QUE VOLVIÓ LA DEMOCRACIA"}

Conocida también como la ley Bustos-Seguel, básicamente impide el despido si los empleadores no están al día en el pago de las cotizaciones previsionales de sus trabajadores. El ex parlamentario admite que está en conversaciones con su partido para retornar al Congreso.

Por ARTuro Castillo Vicencio

El ex combativo dirigente sindical de los trabajadores del cobre, de 58 años de edad, casado, tres hijos y cuatro nietas, prepara su retorno al Congreso, en donde fue diputado durante 16 años. Pese a que no le satisface la forma en que ahora se desenvuelve la actividad parlamentaria, asegura que ya tiene conversaciones adelantadas con su partido, la Democracia Cristiana, para obtener la nominación por el distrito que agrupa a las comunas de San Miguel, Pedro Aguirre Cerda y Lo Espejo.

Por su pasado como dirigente del sindicato de trabajadores de Caletones de Codelco, durante sus cuatro períodos siempre fue integrante de la Comisión de Trabajo de la Cámara Baja e hizo dupla con el desaparecido ex dirigente de la Central Única de Trabajadores (CUT) y también diputado, Manuel Bustos.

Por el momento, se gana la vida prestando asesorías a organizaciones laborales en aspectos previsionales, en proyectos de capacitación con la Organización Internacional del Trabajo (OIT). "Voy a dictar conferencias a donde me inviten", señala.

"Manuel Bustos fue como mi hermano"

\section{¿Cuál proyecto de ley recuerda con más cariño?}

- Bueno, el más emblemático, sin duda, fue la ley Bustos-Seguel, como se conoce. A mí me parece que es legítimo que se llame la ley Bustos, en homenaje a Manuel.

\section{¿Cómo se gestó?}

- Esa es una ley larga en su tramitación parlamentaria y corta en su preparación intelectual. Una vez estábamos con Manuel, que fue como mi hermano en el Congreso, y buscábamos la manera de hacer algo por los trabajadores. Y él me decía: "Oye, Seguel (sic), cómo hacemos para que a la gente le paguen las imposiciones" que todavía es el tema más recurrente en el mundo del trabajo, a pesar de la ley. Empezamos a tirar ideas y se las pasábamos a los abogados que nos asesoraban para que le dieran la forma jurídica a lo que queríamos. Pero con Manuel teníamos dudas de que ese proyecto fuera aprobado, menos con este Congreso como estaba conformado a tan poco tiempo de terminada la dictadura. Y la ley era, básicamente, un método para obligar a los empleadores a pagar las imposiciones. 


\section{¿Y establecía sanciones a quienes no cumplieran?}

- En un principio la idea era que las pagaran. ¿Cómo? Para eso había que ingeniárselas. Una de ellas fue anular el despido si las imposiciones no estaban pagadas, y anular un despido en Chile era sumamente difícil. La cosa se complicaba, porque ¿qué pasaba si había imposiciones impagas hacia atrás, con otro empleador que ya había despedido al trabajador? Entonces, había que hacerlo solo con el último empleador. Nos preguntaban ¿hasta qué monto? Nosotros dijimos sin monto tope, se paga todo lo que se deba. Eso fue lo más duro del debate.

\section{Bueno, entiendo que al establecer montos tope era una forma de condonar la deuda previsional del empleador, ¿no?}

- Claro, era como un crédito blando. Esa fue la parte difícil. La ley tardó dos años en su tramitación.

\section{¿Esa es la ley más emblemática en la que usted participó?}

- Es que esa es la ley más emblemática del Código del Trabajo desde que volvió la democracia. No hay ley en ese código que haya sido más beneficiosa para los trabajadores chilenos. Y la verdad es que yo nunca pensé que fuera a ser aprobada, pero recibimos muchos apoyos, de los sindicatos, de los abogados laboralistas. Manuel y yo tuvimos que hacer mucho lobby.

\section{¿Recuerda cuánto era la evasión de imposiciones que había en ese momento?}

- ¡Uf? Eran miles de millones de dólares. Cuando un trabajador llegaba a viejo, tenía poca plata en su fondo. Solo una cosa nos quedó mal de esa ley, que después yo modifiqué: los despidos se debían hacer en la Inspección del Trabajo, pero los empleadores chantas los empezaron a hacer a través de notarios para evadir el pago previsional. Eso lo descubrí a través de la revista del Colegio de Abogados y corregí esa situación para todo tipo de despidos, cualquiera sea el lugar en donde se realice, para que se acredite el pago de cotizaciones previsionales, de salud y de trabajadoras de casas particulares.

\section{EL SUEÑO DE LA SIESTA}

Durante varios gobiernos, la secretaría de prensa de la presidencia entrega a los periodistas acreditados en la Agrupación de Reporteros de Moneda, más conocida como "La Copucha”, una pauta diaria de las actividades del Jefe de Estado. Llamaba la atención que entre las 15:00 y las 16:00 horas, al menos en los gobiernos de Pinochet y de Aylwin, aparecía el ítem "reunión de evaluación". No se trataba, sin embargo, de que a esa hora los presidentes hicieran una revisión o un repaso a las actividades de la jornada diaria, sino que lisa y llanamente era la hora de la siesta.

Rodolfo Seguel promovió un proyecto de ley que otorgaba el derecho a siesta de los trabajadores. Pese a que muchos parlamentarios, empresarios y otros profesionales admitían en privado la costumbre de la tomar cada día una pequeña siesta, el asunto fue tomado a la broma y la iniciativa no tuvo destino. 


\section{Cuénteme, ¿cuál es la historia de esa ley?}

- Es uno de los cinismos más grandes. Siempre he sabido que muchos duermen siesta. Por mi trabajo de sindicalista recorrí muchos países y me fui preocupando de las horas del descanso de los trabajadores. Y yo soy de siesta diaria, con trabajo o sin trabajo. Para mí es algo fundamental y me dediqué a estudiar el tema observando lo que sucedía en Francia, en España y en Argentina. Junto con eso solicité un estudio a la Comisión Económica Nacional del significado de la siesta en el mundo del trabajo. Hablé con mucha gente y vi que todos los presidentes dormían siesta, los mandatarios tenían camas en La Moneda. Recuerdo que una vez fui a una reunión con Jaime Guzmán para ver el caso de Manuel Bustos cuando estaba relegado en Parral, y pedirle que me ayudara a poner fin al exilio de Manuel; y él me dice: "Rodolfo, tienes que venir después de las 15:30 horas, porque yo duermo siesta". También me preocupé de ver en el Congreso y en todas las oficinas, o casi todas, entre las 14:00 y las 15:00, la mayoría dormía siesta. Yo creo que el 99\% dormía un rato. Planteé esta idea a dos senadores, me apoyaron, pero a cambio me dijeron: "Veamos cómo flexibilizamos la jornada laboral". Y yo me negué a tocar la flexibilidad laboral. Finalmente, pese a que la mayoría reconocía en privado el uso diario de la siesta, incluso los estudios económicos demostraron que un descanso en la mitad de la jornada, deja al trabajador más productivo y comienza la tarde con el mismo ánimo con que llegó en la mañana temprano, pocos me apoyaron. Y, entre ellos, varios de la propia Concertación. Incluso, a esos dos senadores con los que hablé yo los vi con los ojitos rojos lavándose la cara para recibirme en sus oficinas.

\section{¿Y los empresarios qué dijeron?}

- Bueno, recuerdo que al fallecido empresario y abogado Ricardo Claro lo invité a exponer ante la Comisión de Trabajo de la Cámara. Fue y defendió la siesta que él mismo tomaba a diario entre 10 y 20 minutos, y nos dijo que él pensaba que era fundamental que el trabajador duerma un rato entremedio de la jornada laboral.

\section{Pero la ley no pasó.}

- Claro, todos hablaron bien de esa iniciativa, hubo informes económicos, médicos y sociales que nadie pudo rebatir. Y como no encontraron argumentos, echaron el proyecto a la chacota, porque causó cierta hilaridad. Por eso le dije que esta situación dejó al descubierto un enorme cinismo: todos duermen siesta, pero pocos lo admiten.

\section{Si volviera al Congreso, ¿repondría un proyecto de esa naturaleza?}

- Yo creo que lo pensaría, porque en mis entrevistas de esa época yo dije que en Chile, en 20 ó 30 años más, vamos a tener una ley de esa naturaleza.

¿Será necesaria una ley para eso? Le pregunto porque existen países, como Dinamarca, en donde no existe salario minimo porque no es necesario, y la negociación colectiva funciona sin que participe el Estado.

- Si todos los trabajadores de Chile estuvieran sindicalizados, como sucede en Codelco, otro gallo cantaría. Pero si tenemos una sindicalización que no supera el 10\%, y en que se demuestra que a la gente no le interesa el sindicato, no se puede hacer mucho. 


\section{¿Ypor qué a los trabajadores no les interesa sindicalizarse?}

- Porque hubo una cultura en Chile durante la dictadura, que quedó pegada, en que se decía que los sindicatos no servían para nada. Y aquí al empleador no le gustan los sindicatos. Y, obviamente, si tuviéramos organizaciones de trabajadores como las que existen en Suiza o en Francia, en que la resolución de los asuntos no se trata por la vía del conflicto, no necesitaríamos de una ley de la siesta ni de una ley de salario mínimo. Eso se lograría por contrato colectivo.

\section{REFORMA LABORAL}

\section{¿Se ha avanzado en materias laborales a partir de la Reforma Procesal?}

- Bueno, yo trabajé esa ley en el gobierno del presidente Lagos. Nosotros presionamos para avanzar en eso. Antes los juicios eran eternos, en los cuales al final se llegaba a un acuerdo y siempre perdía el trabajador.

\section{¿Y la ley mantuvo el espíritu?}

- La ley es muy buena. Cualquier abogado laboralista o un juez podrá decir lo buena que es porque antes de que los tribunales emitan fallos, invita a las partes a llegar a un acuerdo. Hay una mediación. Y, además, que los plazos para resolver el conflicto se bajen de dos años a 45 días es un logro tremendo. Y, hoy, casi todos los juicios los gana el trabajador.

\section{También hay un defensor laboral.}

- Claro, y ahí nos quisieron meter una cuchufleta, nos plantearon el defensor laboral para todos. No pues, cómo se les ocurre, el defensor laboral es solo para el trabajador.

\section{DECEPCIONADO DEL CONGRESO}

Rodolfo Seguel, como caracteriza a los políticos con formación en el mundo de los dirigentes sindicales, tiene un estilo de expresarse franco y directo. Y, también, se muestra bastante crítico de la manera en que ahora se hace política, especialmente en el Poder Legislativo. "El congreso está siempre en la mente -dice sin que se lo preguntemos-. Pero sabe una cosa, y no es porque yo ya no sea parlamentario, hoy veo a la Cámara de Diputados como algo muy rasca”.

\section{Qué grave lo que dice.}

- Es que creo que faltan políticos de mayor envergadura, de mayor tonelaje. Yo estoy particularmente decepcionado del Congreso, pero hay que fortalecerlo y empoderarlo más. Yo voy bien seguido a Valparaíso y veo que la mayoría de los parlamentarios están prácticamente en lo mismo, lamentablemente, salvo honrosas excepciones. Yo siempre luché durante los gobiernos de Aylwin, de Frei y de Lagos, en los 16 años que fui diputado, para que los congresistas tuvieran especializaciones por área. Resulta que ahora cualquiera habla de todo. Me refiero a diputados que los he visto opinando de todos los temas que están en 
ese momento en la agenda noticiosa, ya sea transporte, salud, educación, delincuencia, y se enfrascan en discusiones con otros parlamentarios. Actúan como si fueran unos genios para manejar con habilidad la agenda pública.

\section{¿No hay especialidad?}

- Exacto, no se han especializado, salvo algunas excepciones. Yo nunca me metí en otros temas que no fueran los propios del mundo laboral y sindical. Yo podía ir como arroz graneado a acompañar a alguien a una conferencia de prensa, pero mis temas laborales no me los tocaba nadie. No sé si actué de forma un poco dictatorial en ese sentido, pero no dejaba que nadie se metiera en mis temas laborales. Y para eso siempre tuve el respaldo de mi partido y de la Concertación. Yo estuve los 16 años como parlamentario siempre en la comisión de Trabajo y de Seguridad Social de la Cámara.

Pero pese a la opinión tan negativa que tiene del Congreso, usted tiene intenciones de postularse otra vez como diputado.

- Yo estoy analizando esto. Ya tengo 58 años, empecé muy joven en la política y en la vida sindical, pero no quito la posibilidad de volver al Congreso.

\section{¿De qué depende?}

- Depende de que la gente vote por mí.

\section{Sí claro, pero para postularse necesita la aprobación de su partido.}

- Bueno, ya tengo algo de eso conversado en el interior del partido. Hay que ver como vamos con la Concertación. En mi distrito donde yo vivo, está el comunista Guillermo Teillier y alguien me va a tener que acompañar. Tal vez el Partido Socialista y el PPD también quieran un cupo.

\section{"INGRESÉ A LA POLÍTICA A LOS 14 AÑOS"}

Rodolfo Seguel se inició en la vida sindical a los 29 años de edad. En esa época era funcionario de la Contraloría de Codelco y en 1982 fue electo dirigente del sindicato profesional y de obreros de Caletones. "Esa división se terminó y ahora son todos iguales", nos acota.

\section{¿Y eso está bien?}

- Cuando estaban los norteamericanos a cargo de las minas, había una odiosa y terrible diferenciación. Había como cuatro castas y clases de trabajadores, incluso los propios gringos no se mezclaban con los chilenos y tenían casas especiales para ellos y sus familias y casinos aparte con comidas diferentes. También había lugares diferenciados para la recreación. La vida de los obreros era muy dura. Ahora hay más especialización, se pide cuarto medio rendido como mínimo. Pero si va a andar barriendo con la escoba no necesita ninguna especialización, y también ese barrendero puede ascender y llegar a ser jefe si se capacita en el camino. 


\section{Usted partió como dirigente en un periodo muy difícil.}

- En plena dictadura.

\section{¿Y cuál es el balance que usted hace de su vida sindical?}

- Mire, observo una gran diferencia entre el mundo sindical de los años 80 al de 2010. Pero hay algo que nunca debe cambiar en el mundo sindical, y eso es la solidaridad de clase entre trabajadores. Y yo noto que eso se ha perdido. Yo veo, por ejemplo, a los trabajadores de Codelco, a los que están en las grandes empresas, que los que más tienen no hacen nada por los demás. Yo no concibo que cada día en Codelco, a pesar que hay una ley sobre tercerización del trabajo, todavía existan los trabajadores contratados y subcontratados. En muchos casos ambos hacen un trabajo similar, pero no tienen los mismos beneficios, ni el mismo sueldo que los otros, ni la misma seguridad social. También tienen distintos tipos de salud, de viviendas. Eso es vergonzoso.

¿Y cuándo estima que se fue perdiendo la solidaridad de clase?

- En los últimos años. No fue durante la dictadura.

\section{solidarios?}

Entonces, ¿diría que bizo falta una dictadura para que los trabajadores fueran

- No sé si fue necesaria la dictadura. Pero nosotros en Codelco ganábamos bien. Teníamos un privilegio económico por participar en la producción del cobre, que sustenta al país, y eso hay que pagarlo bien, como corresponde. Nosotros teníamos buenas remuneraciones, buen estatus. Pero allí existió algo peor, la dictadura fue atomizando al trabajador, le quitó las leyes, los beneficios, los denigraron, crearon sindicatos paralelos con dirigente sindicales designados y aprobados por la empresa. En ese momento yo era bastante joven, pero tomé la decisión de que había que ayudar a los otros trabajadores del país y dijimos que el problema en Chile no se trataba de cambiar una ley u otra, sino que estaba radicado en el conjunto de la sociedad chilena. Y cuando hablábamos de cambiar al conjunto, nos referíamos, obviamente, a que había que terminar con la dictadura y modificar el sistema político que imperaba en el país. Esa, yo diría, fue la expresión más alta de solidaridad de clase que ha habido en los últimos años. En esa época no había ningún otro gremio que podía poner en jaque a la dictadura. Fíjese que en 1983 el entonces ministro del Interior, Sergio Onofre Jarpa, sacó 80 mil soldados a las calles. Entonces, nosotros dijimos hay que defender esta causa, que era la causa de los trabajadores, y nos movilizamos.

\section{¿En algún momento usted se encontró cara a cara con Pinochet?}

- No, nunca.

\section{¿Qué fue lo más cerca que estuvo como dirigente, al gobierno militar?}

- Lo más cercano fue la cárcel.

\section{¿Muchas veces fue detenido?}

- Entraba y salía. Y yo decía que no había ninguna diferencia estar preso adentro que afuera, ya que todo Chile era una cárcel. 


\section{Usted se fue a Australia en los años 80. ¿Por qué dejó Chile?}

- Mire yo recibí muchas amenazas, siempre andaba con un par de autos adelante y atrás y yo no sabía quiénes eran. Estábamos sumamente fichados, y después, con el tiempo, nos dimos cuenta de que había infiltrados en los sindicatos. Había dirigentes que pertenecían al bando de la dictadura. Yo me fui de Chile por dos años. Tomé una decisión absolutamente personal: o me iba y salvaba mi matrimonio y mi familia, o la perdía. Los sindicatos me tenían demasiado absorto.

\section{¿Yqué hizo allá?}

- Ja, ja... tuve un hijo, el menor, que ahora tiene 22 años. Bueno, trabajé y me ofrecieron muchas oportunidades, especialmente de un compañero dirigente del gremio metalúrgico, pero me pusieron una condición que yo no acepté.

\section{¿Cuál?}

- Que me incorporara al Partido Laborista australiano. Y yo no me quería involucrar en la política partidista de allá. Cuando nació mi hijo y vi que mi familia nuevamente estaba consolidada, tomé la decisión de volver a Chile. Al regreso, me llamaron de mi partido para integrar la lista de los candidatos.

\section{¿Desde cuando milita en la DC?}

- Yo entré al partido a los 14 años. La primera fleta me la dio mi madre cuando se enteró que yo había ido a una marcha de Radomiro Tomic en Talca. Esa fleta la recuerdo con cariño.

\section{¿Y es bueno que los dirigentes sindicales militen en partidos politicos?}

- A mí me gusta porque uno sabe con quién está hablando. Con el debido respeto que me merecen todos los dirigentes sindicales, a mí los independientes no me dan la confianza necesaria como para poder desarrollar una actividad o una conversación privada en la cual uno pueda explayarse en temas que puedan afectar los intereses de otro.

\section{¿Pero no ba sentido, de alguna manera, que ser militante puede coartarle la li- bertad de acción?}

- No, porque los dirigentes sindicales de los partidos, hablo por los de la Concertación, tienen autonomía de vuelo bastante amplia. Cuando fui dirigente sindical e hicimos las protestas, nunca me llamó Gabriel Valdés, que era el presidente de la DC en ese momento, para decirme haga esto o no haga esto otro. Me recuerdo claramente de las frases de don Pato (Aylwin) y de don Gabriel cuando les decíamos que si los dirigentes tomábamos alguna decisión, la llevaríamos a cabo de todas maneras, le guste o no a la directiva. "Es delicado lo que van a hacer, pero si lo van a hacer, que resulte bien", nos señalaban. Y así fue que conseguimos las grandes movilizaciones. Después vino el plebiscito, yo todavía estaba en Australia, esa noche nos juntamos unas 200 personas en mi casa en Sydney para celebrar el triunfo del No. Y regresé a Chile a comienzos de 1989. 


\section{¿Allí tomó la decisión de ser candidato al Parlamento?}

- A mí el partido me pidió que me quedara en Santiago y que fuera candidato por un distrito grande y popular. Fue San Miguel, y obtuve la primera mayoría nacional en votos.

\section{¿Y cómo evalúa los 16 años que estuvo como diputado?}

- Yo voy a decir una estupidez, pero debo decirla. El Estado chileno, especialmente los chilenos que pagamos impuestos, invierte mucho dinero en mantener a los parlamentarios. Piense usted en la cantidad de diputados y senadores que hay, y la dieta de los parlamentarios no es menor, es grande. Yo estoy de acuerdo que se les pague bien para que vivan medianamente cómodos y así poder realizar su gestión. Entonces molesta ver lo mucho que gastamos en el Parlamento y que estos recursos sean mal aprovechados. Mantener un parlamentario es tan caro que el Estado, a través de una ley, debería exigirle un tipo de conducta y un tipo de compromiso con su país.

\section{¿Mayor preparación?}

- Claro, pero no puede haber puros ingenieros comerciales, doctores o abogados. El parlamento debe generar una representatividad de lo que es la población chilena. Yo me preparé cuando llegué al Congreso, tengo 6 semestres de leyes en la Universidad de las Américas, y espero terminar la carrera, aparte de aportar toda mi experiencia como dirigente sindical. Por lo tanto, el Estado debiera obligar al parlamentario a prepararse y a especializarse en algún tema o área que vaya en beneficio del país. No estoy de acuerdo con que haya parlamentarios que engañan a su propio Congreso con dinero y que no les pase nada, o que justifican plata para arriendo de oficinas sin arrendarlas, hacen arreglines por el lado y se llevan $\$ 30$ millones, o que contraten a familiares, esposas cayendo en conductas poco éticas. Entonces veo que hay poco compromiso con el país, y con lo bien que están pagados debieran tener un compromiso total.

\section{¿Y cuando habla de preparación, se refiere a títulos universitarios?}

- Es que una cosa es la educación formal y otra es la preparación. Yo una vez leí una entrevista a un parlamentario, en que una de las preguntas era: ¿cuántos libros ha leído? Y el diputado, que todavía está en ejercicio, reconoció que nunca lee un libro. ¿Se imagina un diputado que nunca haya leído un libro?

\section{¿Yquién es?}

- Es un diputado que lleva muchos años en el Congreso. Prefiero no decir el nombre, solo lo pongo como ejemplo. También hay otros que no sabemos si son mudos o qué, nunca los he escuchado intervenir. Seguro que están ahí por el partido que los nominó. Me acuerdo que hubo un período en que había un parlamentario que entraba a la sala con un tazón de café y un sándwich. Esto me duele, y ojalá podamos modificarlo en algún momento y pedirles una conducta adecuada. Los parlamentarios no tienen ningún nivel de exigencia de comportamiento de educación. 
Rodolfo Seguel es franco y directo para hablar. No tuvo dudas en admitir que está en conversaciones con su partido para volver a la Cámara de Diputados, aunque eso no sea políticamente correcto, porque es muy prematuro para decirlo. Que en democracia se perdió la solidaridad de clase y que la subcontratación, por la forma en que se discriminan las remuneraciones y los beneficios, sigue siendo una injusticia. Que el rechazo a la siesta constituye una actitud cínica de muchos. Y no le parece que se tenga que terminar con la indemnización por años de servicio bajo el argumento que implica la movilidad laboral.

Pero sabe que muchas cosas no se podrán lograr con el actual 10\% de sindicalización que existe en el país y si se mantiene vigente el esquema de la negociación colectiva que se desarrolla como una forma de resolver conflictos, en lugar de negociar acuerdos. 